\title{
Quanto dura uma catástrofe? Nação, indivíduo e trauma na Gripe Espanhola
}

\author{
Paulo VAZ ${ }^{1}$ \\ Nicole SANCHOTENE ${ }^{2}$ \\ Amanda SANTOS ${ }^{3}$
}

Resumo:

Diante dos diagnósticos na mídia de que a pandemia de Covid-19 será traumática, propõe-se uma reflexão sobre os modos de articular sofrimento e futuro. A análise do jornal Correio da Manhã (RJ) durante a Gripe Espanhola sugere que já houve outra maneira de atribuir sentido ao sofrimento, que não o trauma. Dada a suposição hoje prevalente de que a epidemia de 1918 foi traumática e de que houve um silenciamento das vítimas, voltar à cobertura jornalística sobre a Gripe Espanhola pode servir para realçar a singularidade nossa de habitar o tempo.

Palavras-chave: Gripe Espanhola. Nação. Família. Trauma. Individualismo.

\section{How long does a catastrophe last? Nation, individual and trauma in the Spanish Flu}

\begin{abstract}
:
In the face of the media diagnoses that the Covid-19 pandemic will be traumatic, we propose a reflection on the ways of articulating suffering and the future. The analysis of the newspaper Correio da Manha (RJ) during the Spanish Flu suggests that there has already been another way of attributing meaning to suffering other than trauma. Given the prevailing assumption today that the 1918 epidemic was traumatic and that the victims were silenced, going back to journalistic coverage of the Spanish Flu may serve to highlight our uniqueness of inhabiting time.
\end{abstract}

Keywords: Spanish Flu. Nation. Family. Trauma. Individualism.

\section{¿Cuánto dura una catástrofe? nación, individuo y trauma en la Gripe Española}

\begin{abstract}
:
Ante los diagnósticos en los medios de comunicación de que la pandemia de Covid-19 será traumática, se propone una reflexión sobre los modos de articular sufrimiento y futuro. El análisis del periódico Correio da Manhã (RJ) durante la Gripe Española sugiere que ya ha habido otra manera de atribuir sentido al sufrimiento que el trauma. Dada la suposición hoy prevalente de que la epidemia de 1918 fue traumática y de que hubo un silenciamiento de las víctimas, volver a la cobertura periodística sobre la Gripe Española puede servir para subrayar la singularidad nuestra de habitar el tiempo.
\end{abstract}

Keywords: Gripe Española. Nación. Familia. Trauma. Individualismo.

\footnotetext{
${ }^{1}$ Professor do Programa de Pós-Graduação em Comunicação e Cultura da UFRJ (PPGCOM - ECO/UFRJ). Doutor em Comunicação pela UFRJ. E-mail: paulovaz.ufrj@gmail.com. O autor agradece o apoio do CNPq ao projeto de pesquisa "Vítima, Trauma e Testemunho".

2 Doutoranda em Comunicação e Cultura - PPGCOM - ECO/UFRJ. Mestre em Comunicação pela UFRJ. Bolsista CAPES. E-mail: freire.nicole@gmail.com.

${ }^{3}$ Doutoranda em Comunicação e Cultura - PPGCOM - ECO/UFRJ. Mestre em Comunicação pela UFRJ. Bolsista CNPq. E-mail: amandassantos94@gmail.com.
} 


\section{Epidemia, catástrofe e trauma}

A pandemia que experimentamos é uma catástrofe. Segundo o senso comum, catástrofe é um evento trágico, com mortes e sofrimentos, mas que é limitado no tempo, no espaço e na destruição que provoca. É um acontecimento que perturba momentaneamente a rotina, mas que não a aniquila, pois é suposto haver retorno a alguma forma de vida ordinária suficientemente parecida com a vida de antes. A duração de uma catástrofe pode variar: uma guerra pode durar anos, uma enchente ou deslizamento de terra, dias. Mas a sociedade retorna a uma rotina mais ou menos inalterada.

Delineada pelas ideias de imprevisibilidade, surpresa, sofrimento e duração limitada, essa temporalidade suscita um problema maior de solidariedade: quem passou relativamente incólume em relação aos que continuam a sofrer após terem sobrevivido ao evento, aqueles em que a catástrofe deixou alguma marca física ou um traço psíquico doloroso. A maior parte dos indivíduos já voltou à vida ordinária e terá restrições a reconhecer o sofrimento dos sobreviventes que não conseguiram retornar, especialmente aqueles sem contrapartida visível a legitimar suas dores.

Nossa cultura promove o conceito de transtorno de estresse pós-traumático como modo de legitimar cientificamente o sofrimento dos sobreviventes de catástrofe, intimando a sociedade a ser solidária. A Covid-19 não é só catastrófica; é praticamente impossível circunscrever os artigos nos meios de comunicação que afirmam que a nossa pandemia é traumática e causa diferentes sofrimentos psíquicos que perdurarão. Para nossa cultura, catástrofe e trauma são duas faces do acontecimento: o que acontece e o que restará de sofrimento a ser reconhecido no futuro.

Essa segurança na identificação de qualquer evento trágico a evento traumático se estende para o passado. Desde a década de 70 do século passado, a Gripe Espanhola, de esquecida, tornou-se objeto de investigação histórica e midiática. Ao se tornar objeto de investigação do nosso presente, sua natureza de acontecimento também mudou. Não só a estudamos cada vez mais; crescentemente nos convencemos de que foi traumática.

Parte dessa certeza deriva da imensidão de sofrimento que provocou. A gripe causou entre 50 e 100 milhões de mortes, o que supera a soma de soldados mortos na Primeira e Segunda Guerra (KOLATA, 2005). A certeza também deriva da sua velocidade de contágio e mortalidade: a Espanhola paralisava cidades e assustava a todos com a dificuldade de obter medicamentos ou tratamento médico. O horror era visível: a possível morte de um indivíduo 
era indicada pela presença de cadáveres insepultos nos lares ou abandonados pelas ruas. Como não se conhecia a ideia de achatar a curva, os sistemas funerários de vários países entraram em colapso pela rapidez com que os mortos se acumulavam.

O problema com a certeza de nossa contemporaneidade de que ela foi traumática é a escassez de relatos públicos após o evento. Uma resposta a essa escassez é imediata. A pandemia foi esquecida, mas esse esquecimento poderia ter sido não um efeito previsível de sua relativa irrelevância para os que sobreviveram, mas de um silenciamento. Pela imposição de silêncio, o sofrimento não apareceu no espaço público, mas o trauma teria existido e sobrevivido em relatos privados. $\mathrm{O}$ argumento se apoia em teorias do trauma com grande sucesso, especialmente pela sua associação com o holocausto e o movimento feminista (HERMAN, 2015). O traumático resulta da composição do evento trágico com o desmentido, com as diferentes formas de não reconhecer o sofrimento, especialmente sua minimização ou esquecimento. A partir dessa interpretação, a Gripe Espanhola teria sido traumática, mas o trauma foi silenciado nas narrativas oficiais pelo interesse de grupos e instituições poderosas, como os médicos e a medicina (BRISTOW, 2012).

A não-apreensão da epidemia como um trauma tampouco se deve à ausência de conceito para descrever a experiência. O conceito de trauma psíquico estava disponível para apreensão e descrição de comportamentos e experiências ao menos desde o final do século XIX. De fato, a pandemia foi contemporânea do fim da Primeira Guerra Mundial, e as narrativas de sofrimento dos soldados foram particularmente relevantes para a própria elaboração do conceito de trauma pela psicanálise e pela psiquiatria (FASSIN; RECHTMAN, 2009).

Podemos tomar Freud como testemunha privilegiada dos efeitos psíquicos de acontecimentos no início do século XX; ele escreveu vários artigos entre 1913 e 1920 sobre a Primeira Guerra, articulando-a com os temas da finitude, do luto, do trauma e da pulsão de morte. Ao mesmo tempo, não dedicou uma linha sequer às experiências de sofrimento dos indivíduos na Gripe Espanhola. Por que a guerra e não a gripe, se o sofrimento que esta provocou foi bem maior, ao menos segundo a nossa métrica do número de mortos?

Mesmo admitindo a suposição de que o sofrimento não tenha tido abertura social para ir ao espaço público, o desafio para os historiadores é a raridade dos relatos sobre a epidemia nos espaços privados. Por que os historiadores não encontram testemunhos de indivíduos sobre o sofrimento experimentado, mesmo se debruçando sobre cartas e diários de indivíduos 
comuns ou célebres?

Outra possibilidade, raramente considerada pela historiografia, é a de que talvez a epidemia de 1918 não tenha sido traumática. Pensar que ela é traumática não é apenas anacrônico, não é apenas exportar para os seres humanos do passado nossas crenças sobre as relações entre psiquismo e acontecimento trágico. Significa supor, primeiro, que a quantidade de sofrimento decide sobre seu potencial traumático e não sua qualidade, isto é, como um determinado acontecimento trágico questiona um modo culturalmente hegemônico de atribuir sentido ao sofrimento. Significa, sobretudo, a naturalização do modo como nossa cultura atribui sentido ao sofrimento que resta após um evento. Estamos supondo tanto que o modo de os "sobreviventes" (e as aspas significam aqui que essa figura talvez seja só contemporânea) darem sentido ao sofrimento após o evento, quanto o reconhecimento social desta condição é, ou deveria ser, a mesma em diferentes culturas.

O anacronismo procura fundar as crenças do presente por descobri-las no passado. Impede, portanto, de usar o passado para pôr em questão as crenças que se tornaram óbvias no presente; impede, sobretudo, de investigar o passado para fazer emergir o conjunto de valores e práticas que permite ao nosso modo de explicar sofrimentos habitar o lugar do verdadeiro. Quem acredita no conceito de estresse pós-traumático toma como espantoso que um acontecimento que causou tantas mortes e destroçou tantas famílias tenha sido silenciado. Se estabelecemos uma distância cética em relação a esse conceito, o espantoso se torna a necessidade contemporânea de insistir que um acontecimento trágico foi traumático. Por que, para nós, catástrofes atuais ou passadas são traumáticas? O que nos faz supor que a Espanhola foi traumática talvez não seja apenas a vastidão do sofrimento que causou, mas também o desejo de universalizar nosso modo de atribuir sentido ao sofrimento, especialmente a relação que um "sobrevivente" deve estabelecer com o evento. Talvez os homens de outrora tivessem outro modo de se relacionar com seu futuro.

Diante da hipótese de que a epidemia de Gripe Espanhola teria sido traumática e suas vítimas silenciadas, propomos um desvio, estabelecendo a possibilidade conceitual de que já houve outro modo de lidar com o sofrimento que perdura. Como modo de experimentar essa questão, analisamos o jornal Correio da Manha ${ }^{4}$ no período de 16 de setembro a 16 de novembro de 1918, resultando 62 edições. A pesquisa se deu pela busca por palavras-chave (grippe, influenza, hespanhola) na Hemeroteca Digital da Biblioteca Nacional. Ao recorrer à cobertura jornalística da época, damos atenção à raridade dos discursos para pontuar em que

\footnotetext{
${ }^{4}$ A escolha por este veículo se deu por sua relevância para a imprensa nos primeiros anos da República e por ser um jornal de oposição ao governo, tendo sido objeto de diversas pesquisas sobre a Gripe Espanhola no Brasil.
} 
medida aqueles enunciados eram singulares, mas, principalmente, a partir deles, ter clareza sobre as crenças do presente, também historicamente determinadas.

\section{Individualismo e antecipação do futuro}

O conceito de transtorno de estresse pós-traumático, formulado pela primeira vez no DSM-III (1980), define nosso modo de lidar com o sofrimento que resta após o evento: por definir o que pode um acontecimento e por pensar a duração de uma experiência pela mudança de comportamento que suscita. Mas o que acontece com o sofrimento que perdura quando não há o conceito de estresse pós-traumático ou, mesmo havendo, quando não se pensa em aplicá-lo às experiências causadas por uma catástrofe?

Para pensar a questão, será necessário recuar aos nexos entre finitude e antecipação de futuro. A ascensão do conceito de trauma será vista então como uma forma singular de articular finitude e futuro, aquela em que as antecipações se limitam ao que acontece antes de nossa morte. Geertz (2005) fez uma observação profunda sobre o modo de suportar nossa finitude de um ponto de vista secular ao comentar o tsunami na Ásia em 2004:

Fatalidade em tal escala, a destruição não só de vidas individuais mas de populações inteiras, ameaça a convicção que talvez melhor reconcilie a muitos de nós, se algo intramundano é capaz de o fazer, com nossa mortalidade: embora nós possamos perecer, a comunidade na qual nascemos, e o tipo de vida que ela sustenta, continuará a existir de alguma forma (GEERTZ, 2005, p. 5).

Em outras palavras, a continuidade intramundana de uma comunidade permite aos seus membros conceberem um futuro secular para além da sua morte e agirem no presente tendo em vista esse futuro, se porventura são capazes de se projetar nessa continuidade.

Há modos historicamente diferentes de permitir a um indivíduo qualquer conceber um lugar para si nessa continuidade intramundana, diferentes modos de "estar lá" após ter morrido. Limitando-nos à história ocidental, temos, primeiro, a conhecida escolha de Aquiles por morrer jovem e cheio de glória ao invés de idoso, mas sem renome. Percebe-se que é a crença numa continuidade de sua sociedade o que sustenta o desejo de Aquiles e o rigor moral com que, escolha feita, enquadra sua vida.

Ainda na cultura grega, um exemplo posterior é a prática da estética da existência analisada por Foucault (2014) e que caracterizava um modo de se projetar nessa continuidade dos indivíduos masculinos pertencentes à elite grega. $\mathrm{O}$ uso temperante dos prazeres concedia à vida dos que o adotavam uma beleza singular que os tornava dignos de serem guardados na 
memória. As restrições aos prazeres sexuais que os indivíduos adotavam nessa vida dependiam, portanto, de uma projeção de permanência na duração da sociedade. Para os gregos e os romanos, a família também era ocasião de se projetar num futuro após a morte, pois permitia aos indivíduos "sobreviver através dos seus filhos" (FOUCAULT, 2014, p. 152). A ascese sexual se legitimava, assim, tendo em vista a continuidade de sua família e a construção de uma vida digna de ser lembrada. Essas duas formas de os indivíduos se projetarem para além de sua morte dependem da suposição inquestionada de continuidade intramundana da sociedade.

Acostumados com a ideia de paraíso cristã, essa forma de permanência surpreende - e desaponta. Os seres humanos continuam após sua morte porque no futuro serão lembrados, com alguma gratidão, pelos seus atos heroicos, seus pensamentos, suas obras de arte ou comportamento moral. De um lado, essa permanência tem a forma da obra, o que é claro no caso da continuidade pela família, pois os fillhos "foram feitos" pelos pais; mas também vale para sociedade, pois teria sido mantida ou aperfeiçoada pelos feitos ou pensamentos grandiosos de alguns indivíduos. De outro, é uma continuidade através da descendência e da memória e, portanto, sem consciência de si. Estranha imortalidade, pois o indivíduo, enquanto tem consciência, jamais terá certeza se será lembrado; se lembrado for, não estará mais lá, não terá consciência para regozijar-se com o reconhecimento. O indivíduo permanece, mas na consciência dos outros. Com exceção da continuidade familiar, a dependência dessa permanência para com os conceitos de honra e glória torna essa forma de projeção acessível apenas a uma minoria. Sua condição é o indivíduo se destacar do comum (GROS, 2006).

$\mathrm{O}$ advento do Cristianismo no ocidente afetou profundamente o modo de se projetar num futuro após a morte. Criou a ideia de uma continuidade extramundana. Uma permanência em "outro lugar", sem sofrimento e morte; para tornar mais atraente essa continuidade, ainda ocorre com consciência de si, isto é, efetivamente como permanência individual, pois o indivíduo sabe que continua vivo. A condição para essa imortalidade verdadeiramente bemaventurada é o comportamento moral rigoroso, mas que é acessível a qualquer um. Essa forma de um indivíduo se projetar para além de sua morte gera a irrelevância das formas seculares, intramundanas, de continuidade. De fato, é proposto que este mundo e tudo o que nele existe desaparecerá. Claro que os seres humanos continuarão a se projetar considerando a continuidade intramundana e se arriscarão pelo renome através da política, da arte e do pensamento, mas o discurso promovido pelo Cristianismo frisa o apocalipse e insiste que a 
glória e a beleza são efêmeras (DELUMEAU, 2009).

Se a Modernidade é definida pela "morte de Deus", como quer Nietzsche (2018) ocorre uma crescente descrença na possibilidade de continuidade extramundana e, portanto, emerge a necessidade de se encontrar outro modo de dar sentido ao sofrimento e legitimar restrições nos comportamentos dos indivíduos. A continuidade intramundana volta a ser atraente; o peso maior da ideia de igualdade, oriundo do próprio desenvolvimento do Cristianismo, impõe a democratização nas formas de os indivíduos nela se projetarem. Embora volte a ser atraente e legítimo notabilizar-se por atos e pensamentos, será preciso haver formas democráticas de se projetar na continuidade intramundana: além da família, os conceitos de progresso e, sobretudo, nação ocuparão esse lugar. O argumento de Benedict Anderson sobre a nação como secularização da religião é crucial:

\begin{abstract}
A fé religiosa declinou, mas o sofrimento que ela ajudava a apaziguar não desapareceu. A desintegração do paraíso: nada torna a fatalidade mais arbitrária. $\mathrm{O}$ absurdo da salvação: nada torna mais necessário um outro estilo de continuidade. Então foi preciso que houvesse uma transformação secular da fatalidade em continuidade, da contingência em significado. [...] poucas coisas se mostraram (se mostram) mais adequadas a essa finalidade do que a ideia de nação (ANDERSON, 2008, p. 38).
\end{abstract}

Talvez a forma mais imediata de perceber a relevância da ideia de nação para a atribuição de sentido ao sofrimento seja pelo sacrifício da vida. Os monumentos aos mortos em guerras se multiplicaram desde o início do século XIX; especialmente na forma do tributo ao sacrifício anônimo, consagram a crença de que os soldados mortos participaram ativamente da continuidade no tempo da nação. O soldado morre, mas a nação é eterna. Forma curiosa de projeção na continuidade da nação: o indivíduo não precisa se destacar dos demais, nem ser lembrado como tal para se conceber como presente no futuro da entidade que ajudou a construir. Continuidade sem consciência de si e sem sequer presença singular na consciência dos seres humanos do futuro; continuidade, portanto, que se reduz a estar presente na entidade supraindividual que o indivíduo ajudou a dar continuidade e a desenvolver. Embora também desapontadora se comparada à permanência com consciência de si cristã, é uma forma de se projetar num futuro para além da sua morte individual e que permitiu a muitos indivíduos desejarem morrer em nome dele. Mais genericamente, graças à duração da família e da nação, muitos modernos aceitaram restrições no presente para obter o futuro desejado; no caso, a continuidade e grandeza da nação e da família.

A possibilidade do sacrifício último pelo bem da nação implica, como caso menor, a 
capacidade de suportar o sofrimento que perdura após o evento. Se a projeção na duração de uma entidade maior que o indivíduo é suficiente para que ele se disponha a morrer, com mais razão é capaz de suscitar o desejo de suportar o sofrimento pelo bem dessas entidades que o atravessam, mas que o arrastam em seu movimento. A recomendação insistentemente repetida era a de seguir em frente, suportar, pois "a vida continua".

Essa expectativa social lançada aos indivíduos sobre o sofrimento após a catástrofe é vista com clareza na Primeira Guerra. Enquanto estava em guerra e, portanto, enquanto a própria nação não era questionada pelo sofrimento que causou, o indivíduo que afirmava ou demonstrava estar com problemas psíquicos era acusado de narcisismo ou de estar usando a doença para fugir das trincheiras. Não queria se sacrificar pela nação; acreditava que sua sobrevivência estava acima dos interesses nacionais. Após o término, quando a guerra se revelou em sua dimensão trágica, o trauma tornou-se legítimo e as nações europeias tenderam a reconhecer o sofrimento dos soldados gravemente afetados pelo horror das trincheiras (FASSIN; RECHTMAN, 2009).

Genericamente, enquanto se continua a acreditar em nação e família, a insistência em exigir o reconhecimento de que se sofre será vista como moralmente negativa e a suspeita pesará sobre o testemunho do sofredor. Inversamente, quando as ideias de família e nação perdem seu peso na vida dos indivíduos, quando se acentua o sofrimento que são capazes de provocar com o sacrifício que demandam, mais será legítimo exigir o reconhecimento do sofrimento.

Compreende-se por que os movimentos feminista e de veteranos do Vietnã foram decisivos para o surgimento do conceito de estresse pós-traumático (FASSIN; RECHTMAN, 2009). O movimento feminista, por denunciar que a família é um lugar de violência doméstica, estupro e pedofilia. O movimento de veteranos, por insistir que a guerra inventada por governantes é o que leva um soldado a agir contra seus códigos morais e a sofrer na extrema proximidade da morte e, por essas duas razões, continuar sofrendo após o retorno. Em suma, a nação e a família, essas instituições com as quais os indivíduos podiam se projetar num futuro além de sua morte e se propor restrições que acreditavam legítimas no seu modo de ser, mostraram-se causadoras de sofrimento.

A crise da nação e da família tem uma face temporal. De fato, indica mais um elemento a compor a temporalidade dos indivíduos contemporâneos: só antecipar o futuro individual antes da morte. Somos indivíduos livres e precários, libertos das amarras do 
trabalho padronizado, dos sindicatos e das obrigações familiares, mas, por isso mesmo, obrigados a encontrar em nós os recursos que nos permitem sobreviver. A descrição inclui, então, como elemento crucial, a tendência a crer que o futuro individual depende do mérito, que a saúde, a riqueza e a vida amorosa dependem da qualidade das escolhas e dos esforços individuais. Somos também, por essa libertação das instituições, indivíduos sem longo prazo, obrigados à competição e à plasticidade, receosos de nos comprometermos com escolhas que limitem o leque futuro de escolhas. Também faz parte dessa temporalidade o esforço de estender ao máximo a nossa duração nessa vida, tornando-nos então capazes de ter prazer por muito tempo e dispostos a nos experimentar em diferentes possibilidades de ser. Essas dimensões se compõem com as antecipações de futuro limitadas ao que pode existir antes da morte. Estender a duração, gozar o máximo que for possível enquanto der, exigir que nada nem ninguém limite suas experimentações de ser, tudo isso ganha relevo quando não há mais continuidade intramundana de entidades coletivas onde projetar seu desejo.

O que acontece com esse indivíduo que só antecipa o futuro antes de sua morte quando passa por uma catástrofe e seu sofrimento permanece? Propor que ele suporte o sofrimento ou tentar silenciar sua demanda de solidariedade significa, do ponto de vista limitado ao futuro antes da morte, reduzir suas possibilidades de ter prazer nessa vida, significa uma injustiça profunda pela desigualdade em relação aos indivíduos que retornaram à vida normal. Além de sofrer, tem suas possibilidades de ser comparativamente reduzidas - e em nada contribuiu para a existência dessa redução, pois a razão é ter passado por uma catástrofe.

Em suma, enquanto houve família e nação, o conceito de trauma tendeu a não ser tão relevante; só se tornou quando se atribuiu a elas a causa do sofrimento. Ao mesmo tempo, quando a nação e a família são desvalorizadas, quando não orientam mais as antecipações de futuro dos indivíduos, então o problema do reconhecimento do sofrimento pós-evento tornase socialmente crucial, e o conceito de trauma tem imensa relevância ética. Assim, a possibilidade de haver ou não futuro intramundano após a morte no qual se projetar explicaria por que a Primeira Guerra foi considerada traumática pelos seus contemporâneos, o porquê de a Gripe Espanhola, apesar de seu imenso impacto, não ter sido considerada, e por que a Covid-19 certamente o será, mesmo tendo um impacto bem menor, segundo a métrica simples do número de mortos. 


\section{A Influenza Hespanhola}

A chegada da Gripe Espanhola no Brasil foi marcada por dois eventos que ocorreram no final de setembro: a chegada do navio inglês Demerara com enfermos a bordo e a notícia do falecimento de oficiais da divisão naval e da missão médica brasileira quando estavam a caminho da guerra. No mesmo mês, os primeiros casos da gripe surgem nas cidades do Rio e Niterói; porém, durante alguns dias as autoridades descartaram se tratar do mesmo mal que grassava na Europa, afirmando ser uma "grippe de caracter benigno, não se tratando absolutamente de “influenza hespanhola"” (NÃO É..., 1918, p. 3).

Quando enfim se admitiu que era de Gripe Espanhola a epidemia que já se espalhava com alguma intensidade no Brasil, o discurso ainda procurava minimizar o pavor da população. No dia 10 de outubro, o diretor da Saúde Pública Carlos Seidl expôs algumas considerações, como a de que a "benegnidade, geralmente reconhecida na grippe, não justifica o terror que por vezes se apodera de algumas pessoas, diminuindo-lhes a resistencia organica e abrindo as portas á infecção" (A “GRIPPE”..., 1918, p. 3)). O Correio da Manhã repetiu diversas vezes que o pavor era maior do que a realidade dos fatos e que o medo só agravava a situação: "a medicina de outrora considerava que o abatimento moral e o medo predispõem a receber o contágio" (DELUMEAU, 2009, p. 182).

Mesmo quando o número de doentes leva o comércio a fechar, o jornal parece se preocupar mais com a vida da cidade do que com a gravidade da epidemia:

Tem a epidemia, porém, caracter tão grave, que autorize o abandono da cidade, tornando a Avenida quasi morta, deixando os bars sem movimento, as casas de espetaculos ás moscas, os cinemas vasios? Diz-nos que não a Saude Publica. Trata-se de um mal commum, a grippe, que tanto faz se sentir de quando em vez no Rio. Por que, pois, o terror? (A EPIDEMIA..., 1918, p. 1).

A comparação da Gripe Espanhola com outras moléstias comuns na época também era recorrente no jornal, principalmente com a febre amarela, insistindo que a gripe era benigna, "nada de comparavel, nos seus effeitos, com as [epidemias] de febre amarella que por tão longos anos flagellaram, todos os verões, a nossa formosa cidade" (VIDAL, 1918, p. 2). Quando a Espanhola começa a esmaecer, rapidamente o medo passa a ser a iminência de uma nova epidemia, dessa vez mais violenta, como a do cólera: "O mundo occidental já estava lutando a braços com a influenza, que dia a dia ceifa vidas em flor, e eis que se anuncia agora o risco da invasão tambem do cholera asiatico" (TOPICOS..., 1918, p. 2). O pavor não se 
justificava porque as epidemias eram eventos relativamente frequentes.

Mesmo quando se narrava o sofrimento das famílias, isto é, o sofrimento na esfera privada, essa narrativa sublinhava questões de ordem material, prática, como a remoção dos corpos dos que haviam falecido em casa, o caos nas funerárias e, enfim, a situação financeira dos lares atingidos pela gripe. A família surge mais como uma instituição, uma unidade econômica, marcada pela ideia de continuidade por descendência, do que como um grupo de indivíduos ligados afetivamente: "Mães, perderam filhos, arrimos de sua velhice. Paes perderam filhos, esperanças do futuro. Creanças perderam seus paes e se acham orphãos, na miseria. Irmãs, sem a protecção de seus irmãos, mulheres, sem o amparo de seus maridos!" (FRANÇA, 1918, p. 3).

O indivíduo se localizava no seio familiar e se orientava por esta relação, que indicava uma obrigação, um compromisso que se devia honrar. O jornal denunciava a situação embaraçosa dos "chefes de família", que, obrigados a arcar com despesas médicas excepcionais, se encontravam desprovidos de recursos para sustentar seus lares, atirados na miséria. Para nossa sensibilidade contemporânea, seria inimaginável encontrar nos jornais um anúncio como este, intitulado "Criança recém nascida":

Um senhor pobre, que acaba de perder sua esposa, victima da epidemia reinante, deixando-lhe cinco filhinhos, inclusive um de 8 dias de nascido, ainda sem registrar, entrega esta criança a uma senhora abastada ou a um casal sem filhos, passando todo e qualquer documento e concordando com o nome que lhe queiram dar (CRIANÇA..., 1918, p. 5).

O destino dos órfãos e das viúvas passou a ser uma preocupação social. Diferente da gripe comum, que faz suas vítimas principalmente entre crianças e idosos, a Espanhola atacou com particular intensidade adultos entre 20 e 40 anos (KOLATA, 2005), o que significou que muitas crianças perderam seus pais e muitas famílias, a sua fonte de sustento. O jornal pedia doações para os orfanatos e, em particular, para as viúvas de oficiais, já que o importante era garantir a sobrevivência econômica dessas pessoas - muito diferente da demanda contemporânea por reconhecimento público do sofrimento psíquico das vítimas. Novamente, nós ficaríamos escandalizados diante da notícia de que 110 menores foram destinados ao Patronato Agrícola, satisfazendo os desejos do presidente da República de "amparar esses e outros orphãos de idêntica natureza" (MENORES..., 1918, p. 1).

Nas notas de falecimento, fica evidente que a família tinha a função de localizar o indivíduo objetivamente dentro de uma longa cadeia cronológica, situando-o no interior de 
uma ordem social (ILLOUZ, 2008, p. 39). Em geral, mesmo quando apareciam na primeira página, as notas forneciam informações curtas e objetivas sobre os falecidos, como nome, idade, estado civil, ocupação, trajetória profissional, nacionalidade e então o nome dos pais, do marido ou de algum parente notável para a sociedade. Por vezes, essas notas mais pareciam o currículo de um familiar da vítima do que uma nota de pesar pela sua morte: "o fallecimento [...] de d. Elisa de Andrade Oliveira, filha do commendador José Maria de Andrade, provedor da Santa Casa da Misericordia do Recife, consul da Belgica e chefe de importante firma commercial [...] A extincta deixa cinco filhos menores." (A “GRIPPE”..., 1918, p. 3).

Como a epidemia acontece simultaneamente à guerra, os primeiros casos noticiados pelo jornal foram dos oficiais brasileiros vitimados pela doença no exterior. Nesse momento, a gripe aparecia subordinada à guerra: suas mortes eram retratadas como um sacrifício em nome da nação, e eram muitas as manifestações de pesar pela perda dos "malogrados patrícios”. Esse pesar, entretanto, não se endereçava às famílias das vítimas. Se essas mortes foram especialmente lamentadas, não foi pela importância da vida particular daqueles indivíduos, mas pelo que eles significavam para a nação, para a "família brasileira": "Morrendo por sua pátria, o cidadão anônimo se realiza pela inscrição numa narrativa imortal que o ultrapassa e o compreende. Ele não é imortalizado como tal, como indivíduo. É a eternidade da narrativa que o atravessa" (GROS, 2006, p. 80). Essa narrativa é a narrativa da nação. Isso também fica evidente em diversas notas nas quais os pêsames são endereçados ao presidente da República (PEZAMES..., 1918, p. 4).

Quando surgiram os primeiros casos de gripe no Brasil, as notícias sobre a guerra ocupavam a primeira página do jornal. Demorou algum tempo até que a epidemia ganhasse destaque nas edições. Apenas em 14 de outubro ela passa a aparecer na primeira página, com a manchete “A 'grippe' alastra-se. Vinte mil pessoas attingidas pela epidemia”, quando a gripe já ia se "alastrando assustadoramente por toda a cidade, cuja vida começa a soffrer as primeiras perturbações” (A “GRIPPE” ALASTRA-SE, 1918, p. 1). Menos de quatro semanas depois, a epidemia desaparece da capa, dando novamente espaço à guerra, apesar da discreta participação do Brasil no conflito. A relevância da guerra como pauta, superando a epidemia que ainda causava centenas de mortes por dia no Rio, é indício de um regime de temporalidade orientado pela nação, e não pelo indivíduo: "Dentro desse tempo, 'o mundo' caminha inexoravelmente em frente" (ANDERSON, 2008, p. 65). 
Esse rápido esquecimento da epidemia nas páginas do jornal poderia ser visto como uma tentativa de silenciamento, como evidências de um "poder" que procurava apagar da memória oficial o sofrimento das vítimas. Essa hipótese perde a força se levarmos em conta, por exemplo, as manifestações populares ocorridas na Avenida Rio Branco em 12 de novembro, após a assinatura do armistício. Para celebrar a vitória dos aliados na guerra, se formou uma "enthusiastica manifestação por parte do povo que se agglomerava na nossa principal via publica" (O SR, NILO PEÇANHA... 1918, p. 1). Essa euforia coletiva, mesmo quando a gripe ainda fazia numerosas vítimas, mostra que a população estava mais interessada nessa agenda das nações, ansiosa para seguir em frente, para o futuro do país.

Figura 1 - Comemoração pela assinatura do Armistício na Avenida Rio Branco

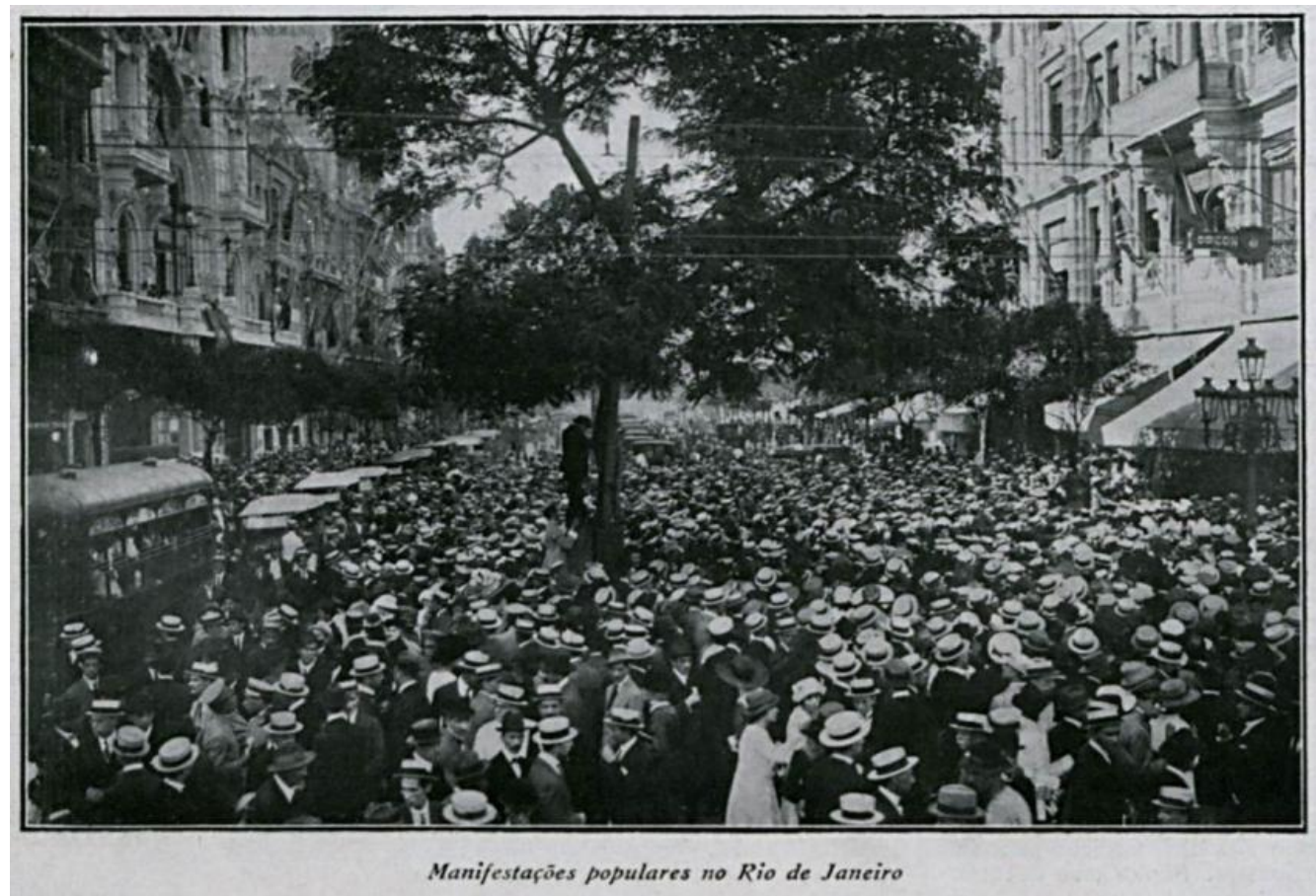

Fonte: Revista Careta (A VICTORIA..., 1918, p. 14). Consultado no acervo da Hemeroteca Digital da Biblioteca Nacional.

Esse desejo por um retorno rápido à normalidade marca uma forma particular de lidar com o sofrimento, certamente diferente da nossa, que se apresenta hoje pela linguagem do trauma. Se hoje a volta à normalidade tende a ser vista como falta de compaixão com as vítimas e seus familiares, naquele momento ela era comemorada como um sinal de que a cidade, essa entidade maior, se recuperava: 
A vida na cidade, desorganizada pela epidemia durante tantos dias, tende a normalizar-se.

[...] O grande pesadelo passou. A cidade, que se liberta dia a dia do enorme flagello da epidemia que a assolou impiedosamente, arrastando-se quasi ao desespero, reanimou-se. [...] A vida diaria, no centro, reentra na sua intensidade habitual de movimentos [...] Os estabelecimentos de ensino, pouco a pouco, reabrem as suas aulas e se não fosse, incontestavelmente, o pavor que se levanta de uma outra calamidade, a convalescença desta capital se estaria operando com a precisa tranquillidade (A VIDA..., 1918, p. 1).

A diferença na sensibilidade na apreensão do acontecimento também se revela na contagem dos mortos nas respectivas epidemias. Em 1918, a contagem parecia servir como modo de indicar a passagem da moléstia, o seu recrudescimento e o sucesso em combatê-la. Hoje, a preocupação é revelar as narrativas pessoais por trás dos números: a vida de cada indivíduo importa e deve ser lembrada. A capa d'O Globo de 10 de maio de 2020 é sintomática: no dia em que o Brasil chegou à marca de 10 mil mortes pela Covid-19, o jornal homenageou as vítimas com a manchete "10 mil histórias". As vítimas são lembradas por aspectos triviais de suas biografias: "flamenguista doente", "boa amiga que amava gatos", "amante de pesca", "orgulhoso dono de um fusca bege 1972", "dono do abraço mais apertado", "um homem inspirador que colecionava tartarugas de decoração" (SETTI; CARIELLO, 2020, p. 1). A trivialidade constitui o indivíduo feliz, o indivíduo como cada um de nós na sua cotidianidade.

O intuito é não deixar que, na contagem dos mortos, as vidas individuais sejam esquecidas, já que isso seria não reconhecer o sofrimento. Transformar as vítimas em meros números seria, em última instância, retirar o protagonismo do indivíduo na cultura: "Para que a dimensão humana da tragédia não se perca na frieza das estatísticas, $O$ Globo homenageia as vidas reunidas em um memorial virtual" (SETTI; CARIELLO, 2020, p. 1.

Ainda sobre o modo como se interpreta o evento catastrófico, vale lembrar que em 1918 o Brasil estava inserido em um processo de modernização. Pelo sanitarismo, buscava-se construir uma imagem republicana pautada pelas ideias de progresso e civilidade. A organização e a higienização dos grandes centros urbanos serviriam para combater as epidemias constantes e para moralizar e fortalecer o povo brasileiro: "Não podemos viver expostos á invasão de todas as epidemias, e nem continuar esta sub-raça de enfermos e depauperados pelas endemias tropicaes" (BELLO, 1918, p. 2). Quando o jornal buscava responsabilizar as autoridades pelo fracasso de evitar a entrada da gripe no país, o que se lamentava era a falta de patriotismo dos agentes públicos, incapazes de proteger as fronteiras 
da nação dos "bacillos estrangeiros":

Deus do céo! Onde é que estamos? Nem a tranquillidade dos nossos lares, nem a sorte do Brasil, invadido pelos bacillos estrangeiros, nada desperta a coragem civica dessas lesmas?

[...]

Mas seria bom á consciencia nacional saber se ha alguma vigilencia alerta ou se estamos em alguma Costa d'Africa, monturo de todos os dectritos alheios e dos germens de todas as infecções de que os outros se livram, achando que somos a esterqueira universal (A EPIDEMIA, 1918, p. 1).

A denúncia enfatiza a situação sanitária da cidade. A epidemia revelaria uma nação marcada pelo atraso e pela barbárie, uma imagem para o resto do mundo do Brasil como um lugar de detritos e germes. Ainda se afirma que a gripe "seria benigna para um povo que possuisse sufficiente cultura hygienica" (UMA DAS VICTIMAS, 1918, p. 3). Na coluna de opinião $O$ Flagello, o articulista reconhece a dimensão do sofrimento causado pela epidemia, ao lamentar o cenário de "desolação sem exemplo nesta cidade". No entanto, se reconforta com a perspectiva de um futuro após a epidemia: "Vendo com magoa a situação de hoje, e bem certos da urgente necessidade da nossa fatal emancipação civica, só nos resta o consolo de cada um trabalhar com fé por apressar a formação da nacionalidade” (MELLO, 1918, p. 2).

Entendendo a epidemia como uma "vultuosa lição" para a nação brasileira, um artigo assinado por "uma das victimas" aconselha: "para que os que ficamos, ainda mal refeitos da catastrophe, saibamos reconhecer o nada que somos, e o muito que podemos ser" (UMA DAS VICTIMAS, 1918, p. 3). Curioso é notar a ambiguidade de sua frase, já que o nada pode se referir ao mesmo tempo ao atraso do Brasil ou à própria existência. Que o sofrimento seja visto como uma oportunidade para sermos mais do que somos, para transformação coletiva e abertura do futuro, já assinala a diferença para a temporalidade da experiência do trauma.

\section{Um passado sem trauma, um presente sem futuro}

Para enfatizar a distância nos modos de dar sentido ao sofrimento em 1918 e em 2020, retornemos às descrições feitas das vítimas nos respectivos momentos. Os vitimados pela Gripe Espanhola eram apresentados a partir de suas obrigações perante a sociedade: a família, o trabalho e a nação. Especialmente quando se tratava de oficiais militares, os feitos na carreira eram narrados com minúcia, ressaltando suas qualidades nas atribuições ou seus préstimos à sociedade: “O dr. Araujo Campos deixa uma fé de officio muito honrosa, tendo prestado relevantes serviços na campanha do Contestado" (MORRE..., 1918, p. 3); “dr. 
Octavio Siqueira de Queiroz, cavalheiro de finas qualidades, quer intellectuaes, quer moraes" (VICTIMAS..., 1918, p. 1). No caso das vítimas da Covid-19, o que caracteriza o indivíduo é sempre de caráter eletivo, como um traço da própria personalidade, com descrições subjetivas e que ressaltam estados positivos: suas paixões, seus laços afetivos, seus temperamentos etc. Por exemplo, quando se faz alusão às profissões, o que se procura ressaltar é o amor pelo ofício: "Não era só dentista, era criadora de sorrisos", "Realizou o sonho de se tornar enfermeiro e amava ajudar a salvar vidas" (SETTI; CARIELLO, 2020, p. 1?).

Em relação às famílias, novamente o aspecto emocional se destaca nas biografias das vítimas contemporâneas: "Apaixonado pai de duas meninas", "Adorava colocar colchões na sala para assistir aos desfiles das escolas de samba com os netos", "Quando ela se divorciou, a vida recomeçou". Este último parece revelar uma ruptura daquela noção de família como continuidade intramundana: na verdade, a vida do indivíduo "começa" quando a da família se rompe. O parentesco já não implica num dever: o que une os indivíduos é o laço afetivo, o desejo do indivíduo investido naquela relação. Em 1918, a obrigação para com a família fica evidente nesta nota de falecimento: "O finado contava 40 annos de edade, era solteiro, natural do Estado do Rio, deixando em completo estado de privação tres irmãos e varios sobrinhos, de quem era o unico arrimo" (VICTIMAS DA PANDEMIA, 1918, p. 3).

Se a epidemia de 1918 não foi traumática, talvez isso se deva ao fato de que havia instituições das quais os indivíduos faziam parte e que davam sentido ao sofrimento, algo pelo qual seguir em frente, isto é, serviam como um "para quê" do sofrimento e da morte. Tanto a família quanto a nação, enquanto comunidades que duravam mais do que o indivíduo, permitiam que o sofrimento individual pudesse ser visto como um sacrifício por um bem maior, ou uma experiência que, por mais dolorosa que fosse, deveria ser suportada e superada. $\mathrm{Na}$ Modernidade, a pátria e a família estavam atreladas à ideia de um futuro a ser construído, algo que duraria mais do que o tempo de uma vida, uma história que continuava para além da experiência de cada pessoa e que permitia que o indivíduo não ficasse paralisado diante do sofrimento.

Por serem parte de algo maior, era preciso não apenas morrer, se sacrificar, mas também esquecer, para que houvesse continuidade. Por essa duração das instituições, havia também outra percepção sobre a temporalidade. Há algo pelo qual o indivíduo contemporâneo está disposto a se restringir? Em que entidades o indivíduo poderia se projetar no futuro? A cultura terapêutica emerge quando a família e a nação se enfraquecem. O sobrevivente é a 
figura que marca que o tempo da sociedade é o tempo do indivíduo, e não da nação.

Quando não há entidade maior que o indivíduo, há necessidade de reconhecimento da dimensão do traumático. Não se trata de resgatar a nação ou a família: todos nós sabemos as várias atrocidades que foram feitas em nome delas. O que queremos é problematizar a ausência de futuro coletivo no contemporâneo. Como não existe mais perspectiva de transformar a sociedade, o indivíduo só adianta a própria morte. Não existe mais redenção para o sofrimento na construção de uma coletividade. Trata-se de um estilo retórico essa maneira de caracterizar o indivíduo, que constitui o individualismo na sua dimensão temporal. O heroísmo deixa de ser a ascese pela construção de um futuro coletivo e passa a ser, cada vez mais, se afirmar como um sobrevivente de uma experiência traumática. A única guerra legítima é a guerra do indivíduo contra a própria morte. 


\section{Referências}

A EPIDEMIA. Correio da Manhã, Rio de Janeiro, ano 18, n. 7175, p. 1, 19 out. 1918.

A EPIDEMIA da "gripe" toma cada vez maior vulto. Correio da Manhã, Rio de Janeiro, ano 18, n. 7171, p. 1,15 out. 1918.

A “GRIPPE” alastra-se. Correio da Manhã, Rio de Janeiro, ano 18, n. 7170, p. 1, 14 out. 1918.

A “GRIPPE" nos nossos quartéis e o estado sanitário da cidade. Correio da Manhã, Rio de Janeiro, ano 18, n. 7167, p. 3, 10 out. 1918.

A VICTORIA dos alliados. Careta, Rio de Janeiro, ano 11, n. 544, p. 14, 23 nov. 1918.

A VIDA da cidade, desorganizada pela pandemia durante tantos dias, tende a normalizar-se. Correio da Manhã, Rio de Janeiro, ano 18, n. 7194, p. 1, 7 nov. 1918.

ANDERSON, Benedict. Comunidades imaginadas: reflexões sobre a origem e a difusão do nacionalismo. São Paulo: Companhia das Letras, 2008.

BELLO, José Maria. Do sr. Wencesláo ao sr. Rodrigues Alves. Correio da Manhã, Rio de Janeiro, ano 18, n. 7194, p. 2, 7 nov. 1918.

BRISTOW, Nancy K. American pandemic: the lost worlds of the 1918 influenza epidemic. New York: Oxford University Press, 2012.

CRIANÇA recém nascida. Correio da Manhã, Rio de Janeiro, ano 18, n. 7192, p. 5,5 nov. 1918.

DELUMEAU, Jean. História do medo no Ocidente 1300-1800: uma cidade sitiada. São Paulo: Companhia das Letras, 2009.

DSM-III. Manual diagnóstico e estatístico de transtornos mentais. Porto Alegre: Artes Médicas, 1980.

FASSIN, Didier; RECHTMAN, Richard. The empire of trauma: an inquiry into the condition of victimhood. Princeton: Princeton University Press, 2009.

FOUCAULT, Michel. História da sexualidade: o uso dos prazeres. São Paulo: Paz e Terra, 2014. v. 2.

FRANÇA, Eduardo. Tribunal popular de execração pública. Correio da Manhã, Rio de Janeiro, ano 18, n. 7181, p. 3, 25 out. 1918.

GEERTZ, Clifford. Very bad news. The New York Review of Books, v. 52, n. 5, Mar. 24, 2005.

GROS, Frédéric. États de violence: essai sur la fin de la guerre. Paris: Gallimard, 2006. 
HERMAN, Judith. Trauma and recovery: the aftermath of violence - from domestic abuse to political terror. New York: Basic Books, 2015.

ILLOUZ, Eva. Saving the modern soul: therapy, emotions and the culture of self-help. Berkeley, Los Angeles: University of California Press, 2008.

KOLATA, Gina. Flu: the story of the great influenza pandemic of 1918 and the search for the virus that caused it. New York: Touchstone, 2005.

MELLO, Miguel. O flagello. Correio da Manhã, Rio de Janeiro, ano 18, n. 7184, p. 1, 28 out. 1918.

MENORES que embarcam para Annitapolis. Correio da Manhã, Rio de Janeiro, ano 18, n. 7187, p. 1, 31 out. 1918.

MORRE o $1^{\circ}$. tenente Araújo Campos. Correio da Manhã, Rio de Janeiro, ano 18, n. 7176, p. 3, 20 out. 1918.

NÃO É a “influenza hespanhola”. Correio da Manhã, Rio de Janeiro, ano 18, n. 7153, p. 3, 27 set. 1918.

NIETZSCHE, Friedrich. Assim falou Zaratustra. São Paulo: Companhia de Bolso, 2018.

PEZAMES ao presidente da República. Correio da Manhã, Rio de Janeiro, ano 18, n. 7161, p. 4,5 out. 1918 .

O SR. NILO PEÇANHA ovacionado na Avenida Rio Branco. Correio da Manhã, Rio de Janeiro, ano 18, n. 7199, p. 1, 12 nov. 1918.

SETTI, Rennan; CARIELLO, Gabriel. As histórias por trás da Covid-19. O Globo, Rio de Janeiro, n. 31.688,10 maio 2020.

TOPICOS \& noticias. Correio da Manhã, Rio de Janeiro, ano 18, n. 7187, p. 2, 31 out. 1918.

UMA DAS VICTIMAS. Correio da Manhã, Rio de Janeiro, ano 18, n. 7192, p. 3, 5 nov. 1918.

VICTIMAS da pandemia. Correio da Manhã, Rio de Janeiro, ano 18, n. 7179, p. 1, 23 out. 1918.

VICTIMAS DA PANDEMIA. Correio da Manhã, Rio de Janeiro, ano 18, n. 7182, p. 3, 26 out. 1918.

VIDAL, Gil. Epidemia. Correio da Manhã, Rio de Janeiro, ano 18, n. 7174, p. 2, 18 out. 1918.

Submetido em: 30.09.2020

Aprovado em: 10.11.2020 